\title{
perifèria
}

Número 13, diciembre 2010

www.periferia.name

\section{La importancia de la metodología etnográfica para la investigación antropológica. El caso de las relaciones de valores en un espacio asociativo juvenil.}

\author{
Chiara Cerri \\ Universidad Complutense de Madrid y Centro de Ciencias \\ Humanas y Sociales, CSIC $^{1}$
}

\begin{abstract}
Resumen
El artículo presenta, a través de los resultados de un trabajo de campo realizado en el local social de una Asociación Juvenil, la importancia de la aplicación metodológica de las prácticas etnográficas. ¿Qué entendemos cuando hablamos de observación participante, entrevista cualitativa, transcripción, diario de campo, etc.? Sin adentrarse excesivamente en los debates propios de la disciplina sobre el correcto uso de tales prácticas, el artículo, que surge de la experiencia personal de la autora, revela su particular percepción de la metodología etnográfica y la perspectiva teórica que la ha acompañado en el trabajo y orientado en la investigación. Mediante un estudio de caso, el texto analiza de qué forma se configuran y caracterizan determinadas figuras de valores. Estas, que se manifiestan en las conductas, permiten hallar la existencia de un sistema de modelos culturales de determinados principios morales de comportamiento que rigen nuestras identidades y nuestro estar en el mundo.
\end{abstract}

Palabras claves: Trabajo de campo, metodología etnográfica, Asociación, figuras de valores.

\begin{abstract}
This article presents, through the results of a fieldwork done in a space of a Youth Association, the importance of the ethnographic methodology practices. What do we mean talking about participant observation, qualitative interviewing, transcription, field notes, etc.? This article doesn't go deeply into the own discipline's debates concerning the correct use of those practices. Nevertheless, it comes from the personal experience of the author, who shows her particular perception of the ethnographic methodology. This theoretical perspective that has followed her in this work has also targeted the research. Using a case study, this article reveals how some kinds of values are configured and characterized into an associative youth space. The social relationships, into this place, get manifested by behaviours that make possible to find the existence of a cultural model system. This system is determinated by behavior moral principles that govern our identities and our being in the world.
\end{abstract}

Key words: Fieldwork, ethnographic methodology, partnership, figures values

\footnotetext{
${ }^{1}$ Enviar correspondencia a: chiara.cerri@cchs.csic.es
} 


\section{perifèria}

Número 13, diciembre 2010

www.periferia.name

\section{Introducción}

Uno de los requisitos para valorar la calidad de un trabajo etnográfico es la relevancia que adquiere el problema a tratar tras la investigación de campo. En el caso que presento en este artículo el sujeto de investigación no parecía tan relevante en sí mismo, ni parecía encubrir un problema considerable: se trataba de descubrir qué valores movían a un grupo de jóvenes, de un municipio a las afueras de Madrid, a participar en una Asociación Juvenil y a acudir a su local, prefiriéndolo a los espacios ofrecidos por el Ayuntamiento. En sí mismo el tema de investigación no suponía muchas dificultades, pero en el transcurso del trabajo de campo se ha revelado bastante más complejo de lo pensado, ya que descubrir las redes de relaciones y de valores que se mueven en el interior de una Asociación Juvenil, y que al mismo tiempo mueven la realidad de la misma, ha necesitado muchas horas de observación, participación y reflexión, más aún teniendo en cuenta la existencia del local, vital para la creación de relaciones de valores.

Se puede entonces concebir esta investigación como ejemplo de la importancia, en el estudio antropológico, del trabajo de campo y de la correcta aplicación de las prácticas etnográficas. En efecto, tal aplicación ha permitido obtener datos significativos para comprender los verdaderos motivos y los valores que rigen la Asociación y la vida asociativa de los participantes.

Definir con exactitud y concretar objetivamente qué son estas técnicas etnográficas como la observación participante, la entrevista, la transcripción, es difícil. No tanto por sus significados literarios, cuanto por sus significados implícitos a la hora de utilizarlos.

El mismo concepto de etnografía puede ser entendido de manera diferente: como proceso de investigación o modo específico de concebir la investigación antropológica (Velasco y Díaz de Rada, 1997) o como el resultado de la investigación en forma de texto. Wolcott (1994), calificando la etnografía como texto, sugiere considerar esta y las técnicas utilizadas para recopilar datos y conmutarlos en inteligibles, como una transformación. Por su parte, Laplantine (1996) la define como una experiencia física de inmersión total antes que nada. 


\section{perifèria}

Número 13, diciembre 2010

www.periferia.name

Esta última noción puede llevar a entender la etnografía como trabajo de campo, elemento distintivo de la disciplina antropológica, por el cual también se emplean diferentes significados. Para algunos autores indica sencillamente la necesidad de desarrollar la investigación en un espacio concreto (un país extranjero; un barrio; un lugar cerrado como una cárcel; etc.) por un periodo de tiempo relativamente largo. Para otros, alude a un conjunto de técnicas (observación participante; entrevistas; etc.) que permiten el desarrollo de una investigación cualitativa y representan el principal método de la disciplina. Velasco y Díaz de Rada hablan del trabajo de campo como de "una situación metodológica y también en sí mismo un proceso, una secuencia de acciones, de comportamientos y de acontecimientos, no todos controlados por el investigador" (Velasco y Díaz de Rada, 1997: 18). Llobera afirma que el trabajo de campo es lo que "define y constituye el objeto antropológico [...] una técnica de investigación social concreta [que] determina el discurso antropológico mediante la imposición de un cierto contenido y de un cierto ritmo" (Llobera, 1990: 32).

Estas definiciones permiten advertir el carácter confuso de la etnografía y del trabajo de campo. Por lo tanto es difícil definir lo que es cada uno sin tener en consideración el enfoque teórico y los objetivos que mueven los investigadores. La relación entre metodología y teoría es, de hecho, uno de los temas principales de los debates propios de la antropología, que ha llevado la disciplina a pasar por diferentes ideologías como el positivismo, el naturalismo o el interpretativismo. Además, a raíz de las teorías post-modernas, el debate se ha centrado en la importancia de la etnografía como texto y su relación con el lenguaje, y en la importancia de la experiencia personal del investigador en el trabajo de campo.

\section{De qué hablamos cuando hablamos de metodología}

En relación al trabajo de campo, Geertz señala que "el lugar de estudio no es el objeto de estudio" (Geertz, 1988: 33), distinguiendo así el campo del objeto. En efecto, la antropología no estudia los lugares (pueblos, empresas, etc.) sino que se interesa por unos problemas teóricos encuadrados en determinados lugares. Además, hoy en día se ocupa también de fenómenos que están asociados a 


\section{perifèria}

Número 13, diciembre 2010

www.periferia.name

diferentes espacios empíricos concretos. En todos casos, el antropólogo se ve obligado a salir de su casa, salir de su cotidianeidad para entrar en un mundo nuevo, un campo, formado a veces por varios campos.

El trabajo de campo puede definirse entonces como el laboratorio del antropólogo, el lugar donde va en búsqueda de un material empírico que le permita abarcar su objeto de estudio para desarrollar la investigación, en una atención flotante que le permite observar y escuchar sin privilegiar de antemano ningún punto del discurso.

Una característica que se asocia al trabajo de campo es la duración. La mayoría de los antropólogos están de acuerdo en el afirmar que cuanto más, mejor: más tiempo se reside en este laboratorio, más datos es posible recolectar. Es evidente que cuanto más se esté en el campo en estrecha convivencia con los sujetos estudiados, más accesible será adentrarse en sus universos y recopilar informaciones valiosas. Sin embargo, permanecer mucho tiempo no siempre es sinónimo de una buena etnografía. En efecto, la práctica antropológica no es solamente cuestión de tiempo, duración o feeling con los sujetos estudiados, más bien incorpora formación y competencia, y produce nuevos aprendizajes.

El trabajo de campo hace parte del más amplio proceso de investigación etnográfica dentro del cual el antropólogo está movido por su formación y su propensión y, en base a estas, aplica las técnicas de recogidas de datos. No se trata solamente de "coleccionar mariposas" (Barley, 1989: 20) sin más, sino de reunir informaciones empíricas a partir de las cuales desarrollar el análisis del trabajo. Hacer algo interesante con los datos recopilados.

Estas informaciones empíricas se recogen a través de determinadas prácticas etnográficas que el antropólogo elige, en base al objeto de estudio y al campo en el que se encuentra.

La observación participante, método clave en la etnografía desde su introducción por parte de Malinowski, ha demostrado eficazmente su importancia y fecundidad a la hora de obtener datos etnográficos significativos, pero es igualmente difícil definir qué es y cómo se tiene que poner en práctica. Italo Signorini (1998) apunta a la necesidad de que la observación se desarrolle en un clima de participación de

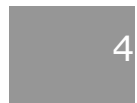




\section{perifèria}

Número 13, diciembre 2010

www.periferia.name

la realidad observada. El investigador se tiene que instalar en la sociedad indagada a través de una inserción amistosa, llegando a ser parte del universo estudiado. Sin embargo, tiene que tener cuidado de no perder completamente su identidad, como si fuera un "extranjero integrado" (Signorini, 1998: 53). Así se fomenta la participación en una normalidad de relaciones que proporciona una mayor observación y sobre todo permite trabajar en espacios más difíciles de alcanzar por sus caracteres íntimos. Otros autores se acercan a esta consideración, insistiendo en que el antropólogo tiene que adoptar un rol marginal, como si fuera un "nativo marginal" (Freilich, 1970) que está dentro y fuera, entre lo familiar y lo extraño. Solamente a través de esta marginalidad puede elaborar interpretaciones válidas (Hammersley y Atkinson, 1994). Porque si la participación llega a ser total, el antropólogo corre el riesgo de volverse nativo. Entrelazar relaciones demasiado amistosas e íntimas con una parte de los sujetos estudiados, puede llevarle a realizar análisis parciales y tener problemas a la hora de relacionarse con otros sujetos. Sin embargo, la participación total facilita un conocimiento más cercano del punto de vista de los nativos, cosa que la observación, aunque sea total, y la participación mínima no permiten. El antropólogo se encuentra así obligado, durante el trabajo de campo, a estar entre dos mundos, el suyo y el de los otros, y a adoptar un rol para el mejor desarrollo de la investigación y para el mejor desarrollo de su vida privada durante el trabajo.

También se puede distinguir la observación participante de la observación ordinaria en base a sus propósitos (Jociles, 1999): mientras la segunda permite ver las cosas sin adentrarse demasiado en profundidad, la primera tiene intenciones de investigación sociocultural y por esto habilita a no dar las cosas por supuesto y prestar atención a todos los elementos considerados significativos. Greenwood, partidario de la Investigación de Acción Participativa (IAP), propone una noción de observación participante dentro de la que define como investigación-acción. El autor en primer lugar diferencia la investigación-acción de la antropología aplicada, definiéndola como un tipo de investigación que se desarrolla en colaboración estricta con los dueños del problema a estudiar y que se concluye con la aplicación práctica de los resultados, para solucionar el problema y fomentar el cambio social 


\section{perifèria}

Número 13, diciembre 2010

www.periferia.name

necesario. En el contexto de la investigación-acción, la observación participante, que según el autor es en sí misma una idea vaga que no explicita el carácter de la participación del antropólogo, deja de producir aquella distinción entre el investigador que observa y los informantes que suministran datos.

Los conceptos de participación y observación se conceptualizan desde el punto de vista de una investigación colaborativa y recíproca y de una iniciativa a favor del cambio social. [...] todos los participantes son, a la vez, participantes y observadores que conjugan sus observaciones con el fin de conseguir unos resultados exitosos. (Greenwood, 2000:34)

De esta forma, se elimina del proceso de investigación la categoría de informantes, ya que se trataría de un continuum de informaciones compartidas, desde dentro y desde fuera, por parte de todos los actores en juego y donde el investigador no es el único a tener el rol de observador y se encuentra además obligado a participar.

En todo caso, es necesario recordar que la observación nunca es totalmente inmaculada, ya que el sujeto que realiza la observación, el antropólogo, tiene sobre sus hombros un conjunto de prejuicios, creencias y nociones que, de forma involuntaria, mueven su mirada. Por este motivo tiene que ser consciente de su rol dentro y durante el trabajo de campo y aplicar el enfoque del etnocentrismo crítico. Con esta expresión, siguiendo De Martino y Lanternari (De Martino, 1977; Lanternari, 1997), se entiende una continua puesta en discusión de las categorías analíticas propias del antropólogo que investiga. Se origina en él el reconocimiento de que está observando al otro a través de unas categorías históricamente y culturalmente determinadas por su propia sociedad.

Además, la observación participante no siempre permite acceder a informaciones importantes, como datos relativos a los discursos y al universo de significados de los actores. Por lo que resulta indispensable complementar el trabajo con las entrevistas.

Es necesario subrayar cómo en las entrevistas también se hace uso de la observación. Es una de sus características: no es oír, más bien escuchar, pero tampoco es sólo escuchar, es también observar y no solamente mirar, como afirma 


\section{perifèria}

Número 13, diciembre 2010

www.periferia.name

Sanmartín Arce (2007). Observar es intensificar la primera ojeada, para mirar bien y mirar todo, distinguiendo lo que se está viendo (Laplantine, 1996).

Como afirma Lisón Tolosana,

En el dialogo pausado con los informantes compartimos tiempo, espacio, palabras, co-experiencias [...] Al comunicar en independencia no sólo les oímos, sino que les observamos describiendo, dando opiniones, evaluando, juzgando. Están actuando. [...] Es precisamente en esos diálogos deferentes, despaciosos y lentos cuando nos percatamos [...] que muchos de los elementos del diálogo referencial son refractarios a consideración estadística o meramente objetiva y tercero y en consecuencia, que no toda realidad se entiende mejor cuanto más objetivamente se analiza. Pues bien, el diálogo in situ es otro de nuestros postulados iniciales como la participación en la vida local. (Lisón Tolosana 2000b: 23)

La entrevista etnográfica se caracteriza por ser una conversación cómoda y bien dirigida donde los informantes, y también el investigador, se relajan y todo toma la forma de un acercamiento y un encuentro natural. Es ese encuentro natural entre investigador e informante que permite que surjan los datos etnográficos sin necesidad de realizar preguntas directas y rígidas.

Hammersley y Atkinson (1994) sostienen que la diferencia entre la entrevista etnográfica y otro tipo de entrevista, como el cuestionario, no es tanto la forma, que una sea desestructurada y la otra estructurada, ya que en realidad "todas las entrevistas, como cualquier otro tipo de interacción social, son estructuradas, tanto por el investigador como por el informante. La diferencia fundamental estriba en que unas son entrevistas reflexivas y otras son estandarizadas" (Hammersley y Atkinson, 1994: 128). La entrevista se compone de preguntas indirectas y abiertas, donde el entrevistador asume una posición aparentemente pasiva, intentando condicionar lo menos posible las respuestas. Al mismo tiempo está continuamente atento a la dirección que toma la entrevista para poderla guiar hacia sus objetivos.

Margarita Del Olmo habla de "entrevista dirigida", como "una conversación con un interlocutor en la que lo que se busca no son respuestas sino preguntas" (Del Olmo, 


\section{perifèria}

Número 13, diciembre 2010

www.periferia.name

2003: 193). Además de preferir el término de interlocutor al de informante, término que sobrentiende unas connotaciones de subordinación, la antropóloga considera que las entrevistas son en realidad un ejercicio de empatía donde el perseguir preguntas es lo que permite encontrar significados, y para conseguirlo la mejor estrategia es pedir relatos.

Una entrevista dirigida no debe hacer preguntas, porque pregunta que hagas, error que cometes. El problema es cómo sortearlas, sobre todo cuando las personas que se entrevistan están esperando preguntas. Pedir relatos, que no es lo mismo que hacer preguntas, y hacer que la gente articule, desde mi punto de vista es una estrategia excelente en una entrevista dirigida. (Del Olmo, 2003: 213-214)

Rosana Guber señala que hay preguntas que el investigador formula que realmente son "preguntas para descubrir preguntas" (Guber, 1991:227): en la primera fase del trabajo de campo, el antropólogo formula preguntas más abiertas para poder construirse un marco de referencia sobre su objeto de estudio y los sujetos que lo completan. En una segunda fase, este marco será lo que permitirá al investigador formular otras preguntas, más especificas y significativas. Se trata de un proceso que une las preguntas con las respuestas para formular nuevas preguntas y recibir nuevas respuestas. Guber, además, entiende la entrevista antropológica como una entrevista informal o no directiva donde, sin olvidar que el investigador siempre está presente en la relación, la no directividad permite corregir el marco de imposición del investigador. Si normalmente en las entrevistas existe una relación asimétrica entre entrevistador y entrevistado, a través de la no directividad es posible crear un encuentro más simétrico, o por lo menos un encuentro donde las posiciones de los dos sujetos, aunque siendo diferentes, no sean ni inferiores ni superiores.

Por lo tanto, igual que la observación, la entrevista puede ser entendida como interacción, conversación y negociación invisibles entre el entrevistado y el entrevistador. Por este motivo, según algunos, con esta técnica más que obtener información, se produce información. Puesto que la entrevista antropológica puede 


\section{perifèria}

Número 13, diciembre 2010

www.periferia.name

ser concebida como escenificación de una relación social entre dos interlocutores, la información que se reúne en este determinado contexto está producida. No obstante, no significa que la entrevista no sea un método científico capaz de dar información, sobre todo porque lo que interesa al antropólogo no es saber si los informantes dicen la verdad o la mentira, sino conocer los significados profundos y las categorías implícitas de sus discursos.

La mayor dificultad que a veces se encuentra en la realización de las entrevistas, es alcanzar los interlocutores, que son los que conceden el acceso a la información. Sea a través de la entrevista o de la observación, el acceso es necesario para el desarrollo de la investigación. Por lo tanto, su negociación acompaña continuamente la recogida de datos, como si se tratase de la misma fase de la investigación.

Los datos recopilados se trasladan añadiendo reflexiones y percepciones en las notas de campo. ¿Cuándo hay que escribir notas de campo? Supuestamente inmediatamente después de la observación de un hecho o una acción significativa, ya que al anotarla más tarde la memoria puede fallar. Lo ideal sería tomar notas al mismo tiempo de la observación y la entrevista, pero no siempre la situación lo permite $y$, aunque lo permitiera, el investigador debería realizar sus anotaciones sin dar demasiado a la vista, sin parecer demasiado diligente o raro, ya que los sujetos pueden pensar mal del desconocido que les observa y escribe en un cuadernito.

Según Velasco y Díaz de Rada (1997) hay que diferenciar entre el cuaderno de campo, o notas de campo, y el diario de campo, siendo el primero un registro de anotaciones inmediatas, o casi inmediatas, tomadas en el campo, y el segundo un registro secundario, sistemático y reflexivo sobre lo que se ha escrito en las notas. Los autores afirman que es imposible establecer las pautas de estas técnicas ya que cada investigador utiliza un método que le resulta más beneficioso y cómodo, pero si que "en cierto modo el diario de campo es la trastienda-taller de la investigación" (Velasco y Díaz de Rada, 1997: 51). Como si el diario representase la descripción más íntima de la experiencia personal del trabajo de campo.

El antropólogo no solamente registra las descripciones de los hechos observados, 


\section{perifèria}

Número 13, diciembre 2010

www.periferia.name

sino que inscribe también la comprensión valorativa que hace de estos. No sólo anota lo que ha pasado en la realidad, sino también sus sensaciones, valoraciones e interpretaciones. Todo esto será luego analizado y revisado para llegar a unas conclusiones y unos resultados. El diario y las notas se configuran entonces como otra fuente de datos necesaria, porque además permiten aplicar el método de la triangulación como garantía de fiabilidad.

Goodall (2000), explicando las características de la "nueva etnografía", sostiene que las notas de campo no son la descripción y representación de la realidad, porque son parciales, partidarias y problemáticas y, además, el lenguaje con el cual son escritas es simbólico. Sin embargo, el autor recomienda utilizar durante el trabajo de campo un diario personal o unas notas profesionales, o ambas cosas. Lo importante es que con estas técnicas el investigador registre lo que observa, lo que piensa y le preocupa, tanto en la vida personal como en la profesional. En fin, registrar las reflexiones acerca de la propia experiencia como investigador en la vida cotidiana. El diario personal contiene informaciones más profundas, más privadas, como si fuera un relato reflexivo sobre la vida del escritor. Pero al mismo tiempo es importante mantener un conjunto de notas de campo donde registrar las observaciones, las representaciones y análisis de las experiencias vividas por los demás. Según Goodall, las notas de campo pueden registrar y representar tres variedades de experiencia: los intercambios verbales entre dos o más personas, como los diálogos informales, los debates y las entrevistas; las prácticas de las personas, en particular sus estrategias y tácticas; las conexiones implícitas, o así interpretadas por el escritor, entre los intercambios verbales y las practicas.

Tener un registro de la vida cotidiana, personal con los diarios y más profesional con las notas, es fundamental. Constituye al mismo tiempo el registro de lo que se ha hecho y pensado durante el trabajo de campo; el relato personal de las reflexiones acerca de lo que se ha escrito y lo que se ha pensado; el mapa gramatical del territorio mental y emocional que se ha desarrollado durante el trabajo de campo.

Goodall, concibiendo la "nueva etnografía" como una forma de comunicación escrita, se centra tanto en la observación y en las consecuentes notas de campo 


\section{perifèria}

Número 13, diciembre 2010

www.periferia.name

que casi no habla de las entrevistas y sus consecuentes transcripciones.

Pero esa es otra técnica fundamental para el trabajo etnográfico. Cada investigador tiene su método de transcripción, algunos con signos que indiquen las pausas y/o las entonaciones, otros sin signos específicos, pero lo importante es que se transcriba correctamente el discurso que se ha grabado y que refleja las condiciones exploradas. Aunque hay que tener siempre en consideración que, primero, lo que dicen los informantes está influenciado por el mismo contexto de las entrevista $y$, segundo, que las interpretaciones sucesivas que hace el antropólogo, por su naturaleza, son diferentes de los relatos de los informantes.

\section{Estudio de caso}

La investigación que se presenta en este artículo se ha desarrollado en el local de la Asociación Juvenil Samsara ${ }^{2}$ en un municipio a las afueras de Madrid. El objetivo principal y originario era entender cuáles son los valores primordiales que llevan a los y las jóvenes a utilizar y frecuentar este local, prefiriéndolo a los espacios públicos que el Ayuntamiento pone a su disposición. Para comprender qué formas simbólicas asume el uso del espacio por parte de estos jóvenes, sean miembros o no de la Asociación, ha sido necesario profundizar en los valores intrínsecos de la misma.

La Asociación Samsara se encuentra en una ciudad a las afueras de Madrid capital de alrededor 120.000 habitantes, donde en los últimos 20 años el gobierno local ha apoyado fuertemente las políticas culturales y sociales para fomentar la participación de los ciudadanos. El municipio cuenta con dos centros culturales que ejercitan las funciones de mediatecas, bibliotecas, salas de reuniones y de talleres, de exposición, de teatro, etc.; una Universidad Popular; una casa de las Asociaciones Regionales; una Casa de la Mujer; una Casa de las Asociaciones y una Casa de la Juventud. Estos espacios permiten el desarrollo de diferentes actividades llevadas a cabo por los técnicos del mismo Ayuntamiento (cursos, exposiciones, espectáculos, etc.) y/o por los miembros de las asociaciones.

\footnotetext{
2 Para salvaguardar la confidencialidad de los informantes, los nombres reales de personas, Asociación y actividades se han ocultado sustituyéndolos con nombres ficticios.
} 


\section{perifèria}

Número 13, diciembre 2010

www.periferia.name

En efecto, una característica del municipio es la presencia de un gran número de asociaciones, sean de vecinos, de actividades culturales y artísticas, deportivas, políticas, etc., debido al interés del Ayuntamiento en fomentar la participación ciudadana ${ }^{3}$.

En lo que concierne al ámbito de Juventud, la ciudad cuenta con alrededor de 40 Asociaciones Juveniles, compuestas por personas de hasta 30 años y con diferentes objetivos (culturales, sociales, deportivas, políticas, artísticas, educativas, etc.).

La Asociación Samsara es parte del grupo de movimiento social y educación no formal, pero se caracteriza y se diferencia de las demás asociaciones del mismo ámbito por dos aspectos en particular:

1. Mientras la demás se dirigen a colectivos específicos (niños y niñas hasta los 12 años; adolescentes hasta los 16 años; jóvenes discapacitados; etc.), Samsara trabaja con un amplio abanico de personas, diferentes por edad (desde los 8 hasta los 35 años), por proveniencia, por residencia, etc.

2. A diferencia de las otras asociaciones de educación no formal que desarrollan sus actividades en espacios concedidos por el Ayuntamiento en determinados días y horarios (por ejemplo, el martes de 17h. hasta 19h.), Samsara tiene a disposición un local abierto de lunes a viernes (el fin de semana sólo si hay actividades concretas) por las tardes y a veces por las mañanas.

El local se encuentra en el barrio centro de la ciudad, el barrio más antiguo y donde en los últimos años se ha concentrado la gran parte de población inmigrante, debido en parte por la oferta de alquileres más baratos. Consta en la primera planta de una sala de recepción-oficina, donde normalmente trabajan los directivos de la Asociación pero que está abierta a todos los miembros y visitantes, y una oficinaalmacén, donde se guardan los instrumentos musicales y hay una mesa con un ordenador. En la planta de abajo, hay una sala organizada como una Ciber Aula con

\footnotetext{
${ }^{3}$ En un estudio sobre la trama asociativa valenciana, Josepa Cucó indica claramente que, para que haya Asociaciones voluntarias, donde los ciudadanos puedan organizarse colectivamente, es necesario que exista un marco democrático. Esto es el caso del municipio en cuestión, surgido como ciudad dormitorio en la periferia de Madrid y donde el gobierno democrático ha fomentado desde el principio una alargada participación ciudadana que ha permitido también vitalizar el espacio socio-comunitario (Cucó, 1991).
} 


\section{perifèria}

Número 13, diciembre 2010

www.periferia.name

cuatro ordenadores, una televisión y algunos juegos de mesa; una sala Chill Out donde normalmente se reúnen una vez a la semana los socios más mayores para hablar de la organización de las actividades de la Asociación y donde se organizan fiestas y/o reuniones informales; y otra sala utilizada para desarrollar diversas actividades, como talleres de yoga, de baile ecuatoriano y de Hip hop.

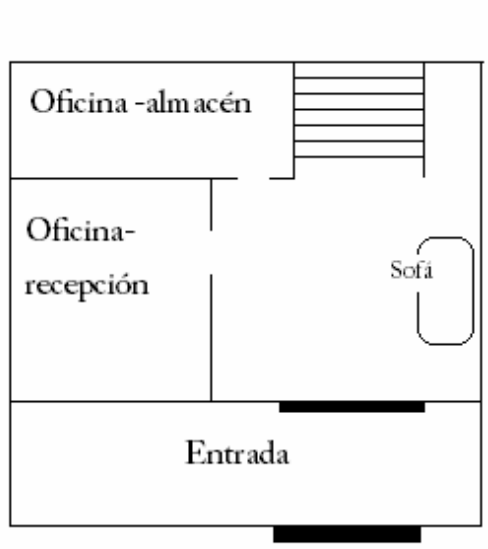

PRIMERA PLANTA

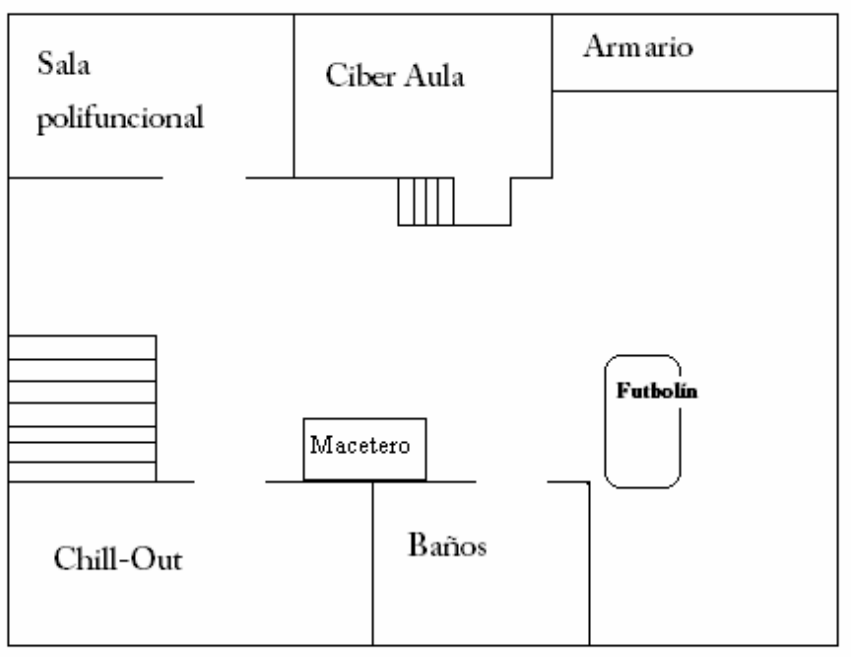

PLANTA BAJA

IMAGEN 1. Plano esquemático del local Samsara (Elaboración propia)

La Asociación trabaja en varios proyectos nacionales e internacionales como el Servicio de Voluntariado Europeo, los campos de trabajo, etc., y su proyecto local es Yumbo: un grupo de percusión que tiene el objetivo de dar a los jóvenes del municipio una opción de ocio alternativo y educar a la convivencia y a la interacción intercultural.

En el curso del trabajo de campo he mantenido como técnica principal la observación participante, a veces tomando parte a las actividades empujada para los mismos miembros de la Asociación, pero he intentado también mantener una 


\section{perifèria}

Número 13, diciembre 2010

www.periferia.name

cierta distancia para permanecer en el equilibrio entre el rol de investigadora y el rol de copartícipe, aunque al final el constante intercambio de experiencias y la continua relación emocional me han hecho cuestionar sobre mi rol dentro del juego interrelacional. En efecto, un aspecto que caracteriza el trabajo de campo es la presencia del investigador en el lugar que, como afirma Jociles:

[...] entraña una transformación no sólo del «locus primario de la investigación», es decir, el conocido paso desde 'la veranda de la misión'(o de 'la cubierta del barco') al 'centro mismo del poblado', sino también de la propia concepción del rol del investigador, que va a tomar ahora su papel de 'inquisidor' por el de 'participante de algún modo' en la vida de la gente que investiga. (Jociles, 1999: 15)

Hammersley y Atkinson afirman que una característica del trabajo etnográfico es su flexibilidad:

[...] puesto que ella [la etnografía] no requiere de un diseño extensivo previo al trabajo de campo, como las encuestas sociales y los experimentos, la estrategia e incluso la orientación de la investigación pueden cambiarse con relativa facilidad, de acuerdo con las necesidades cambiantes requeridas por el proceso de elaboración teórica. (Hammersley y Atkinson, 1994:38)

En mi caso, cada vez que avanzaba en el trabajo, cada vez que creía haber entendido algo sobre las relaciones de estos jóvenes entre sí y con el local, sucedía algo o alguien me decía algo que no cuadraba. Entonces tenía que reformular mis teorías. Tenía que añadir preguntas en las entrevistas para comprender nuevos aspectos que se habían hecho visibles. Tenía que tener más cuidado en la observación, para no perderme algo que podía ser representativo. Todo esto durante y en base al desarrollo del trabajo de campo. Manteniendo mi rol de investigadora pero sin ser demasiado distante de sus vidas. Moviéndome en el límite entre objetividad profesional y emotividad participativa. Porque estar demasiado alejado de la realidad estudiada no siempre es positivo. Cuestionando la

\footnotetext{
${ }^{4}$ Los símbolos ortográficos son de la autora
} 


\section{perifèria}

Número 13, diciembre 2010

www.periferia.name

visión materialista de Harris (1985), que afirma que para un conocimiento objetivo es necesario prescindir de la visión emic para utilizar únicamente un punto de vista externo, considero que hay que participar en esta realidad, hay que acercarse a la visión emic de la realidad a través de la participación para luego compararla con la visión etic de la observación.

El acercamiento a los y las jóvenes de la Asociación y la participación en algunas de sus actividades, ha permitido que la interacción con estos fuera poco a poco más natural. Los y las informantes me revelaban espontáneamente informaciones vitales para la comprensión de su realidad social dentro de la Asociación y del local, aunque no todos me desvelaron el mismo tipo de información. En efecto, las edades de los entrevistados comprenden de los 18 hasta los 24 años, ya que no ha sido posible realizar entrevistas reales a los usuarios más pequeños, sobre todo por la dificultad de establecer una relación de confianza con ellos. Sólo se han podido tener charlas informales que no han permitido recopilar muchas informaciones, debido a las respuestas breves y en la mayoría de los casos monosilábicas de los informantes (sí, no, no sé, etc.). Pero ha sido fundamental estar con ellos y observarlos. Observarlos en sus momentos más íntimos: cuando jugaban a pegarse, cuando veían videos de música en You Tube, cuando participaban en los ensayos o llegaban al local.

Creo que la observación del comportamiento habitual de los actores, dentro del espacio asociativo en cuestión, ha sido en mi caso una fuente de informaciones profundas ya que, en las acciones cotidianas, se revelaban elementos importantes. A través de la observación de la cotidianeidad del grupo he podido divisar aquellos "imponderables de la vida real" (Malinowski, 1973:36), fenómenos extremadamente significativos para comprender las relaciones de valores subyacentes.

En primer lugar, he podido distinguir tres tipos de participantes:

1. Los que van al local solamente para actividades puntuales como los talleres de yoga y de bailes y no están involucrados en la Asociación, tanto que no participan en sus actividades, ni frecuentan el local en otras ocasiones. 


\section{perifèria}

Número 13, diciembre 2010

www.periferia.name

2. Los que no son parte de la Asociación pero van a menudo al local porque son amigos de algunos miembros de Samsara.

3. Los participantes y miembros activos de la Asociación que utilizan el local y van a menudo haya o no actividades.

En este estudio he tomado en consideración solamente los últimos dos grupos, ya que en ellos se encuentran los valores y los contra-valores de la participación, de la experiencia y de la responsabilidad, que se reflejan en las interacciones sociales y en el uso del local.

Una vez adquirida cierta confidencialidad con los actores sociales y una vez que mi figura entró a formar parte de su espacio vital, aunque no sé de qué forma, podía ejercitar la observación y tomar mis notas de campo con más naturalidad. Sobre todo en el caso de las actividades puntuales, como los ensayos de música o la proyección de un video, podía ejercitar una observación puntual y al mismo tiempo reflejar mis reflexiones y sensaciones en el cuaderno de campo. Sin embargo, no siempre tenía la oportunidad de transcribir en vivo mis observaciones, ya que se realizaban al mismo tiempo que la participación, y entonces tenía que tirar de mi memoria para apuntar luego lo que me había parecido más relevante para la investigación.

Asad sostiene que en este caso el antropólogo controla ya desde su cuaderno de notas la operación de elegir y establecer qué frases son propias o impropias. Esta operación crece desde las notas hasta el texto etnográfico, por "devenir en sentencia definitiva" (Asad, 1991: 223).

Otros autores (Gil, 1998) prefieren distinguir entre descripción e interpretación: la primera es la fijación de un hecho a través de la escritura o de la grabación, mientras que la segunda es la explicación de este hecho en base a un determinado punto de vista teórico.

Pero, si partimos del presupuesto que quien efectúa la descripción, en este caso el antropólogo, lleva consigo un bagaje teórico, podemos afirmar que los hechos que describen están de algunas formas predeterminados e interpretados. Una descripción es entonces una elección que el antropólogo hace entre muchas más 


\section{perifèria}

Número 13, diciembre 2010

www.periferia.name

descripciones posibles. Sin embargo, la línea de demarcación entre describir e interpretar es tan fina que resulta difícil separarlas y nos lleva a adoptar la noción de descripción interpretativa o densa. En el pensamiento geertziano el trabajo etnográfico es en efecto una interpretación de interpretaciones, resultado de la interacción social del investigador con los sujetos estudiados, donde el punto de vista de estos es ya de por sí una interpretación, podríamos añadir nativa, de la realidad. Por ejemplo, en las entrevistas los informantes revelan su interpretación de su realidad, no la realidad en sí. Sin embargo, es esto que nos permite captar los significados profundos de sus vidas.

En el estudio aquí presentado, la entrevista ha sido otra técnica fundamental. En primer lugar, la considero como parte de un todo: cada vez que he realizado una entrevista no he podido obviar su contexto y toda la información recopilada anteriormente. Segundo, opino que no se puede limitar a oír sin escuchar: no basta con oír las respuestas de los informantes, hay que dar un paso más, hay que llegar a transformar la entrevista en un diálogo coloquial dentro del encuentro humano que se está realizando en el momento. Con esto no quiero decir que haya que entablar una conversación libre de extenderse por todos los temas que se nos ocurran. Se puede hacer, pero esto desviaría del objetivo específico. Hay que crear un estado de confidencialidad, donde ambos actores (entrevistador y entrevistado) se sientan cómodos e interesados, y dirigir la conversación hacía donde queremos llegar, sin forzar demasiado. Un trato natural con los informantes, tanto en la observación, en la participación como en las entrevistas, permite un mayor acercamiento y una mayor comprensión de su realidad socio-cultural.

En mi caso, teniendo presente el objeto de la investigación, las entrevistas estaban diseñadas para llevar los informantes a hablar sobre el mismo tema, para poder luego comparar las diferentes respuestas. Es verdad que, a causa de la interacción que se creó, en varios momentos las conversaciones se dirigían hacia otros temas, al parecer poco relevantes pero, en la mayoría de los casos, reveladores de nuevos aspectos que al principio de la investigación no me había planteado. Si al principio mi intención era la de comprender porqué una parte de los jóvenes de la ciudad decidía frecuentar el local de la Asociación en vez de los espacios públicos 


\section{perifèria}

Número 13, diciembre 2010

www.periferia.name

ofrecidos, al final, con las entrevistas y la observación participante, me di cuenta que no podía responder a esta pregunta sin comprender cómo se desarrollaban las relaciones y la vida en el interior de la misma Asociación primero y dentro del espacio social segundo.

Eso también explica por qué, a la hora de efectuar las entrevistas, he decidido hacerlas en espacios conocidos para los informantes: en su propia casa y en el local de la Asociación, en particular en la sala llamada Chill Out: una sala de reuniones y encuentros informales que los actores sociales ya habían definido con significados propios. La sala Chill Out ha sido en efecto el principal escenario de las entrevistas, ya que este espacio, compuesto por sofás, luces bajas y anaranjadas, es un espacio que incita a la confidencialidad, permitiendo la creación de aquel encuentro humano necesario para el correcto desarrollo de la entrevista.

\section{Análisis de resultados}

En relación a la estructura de la Asociación, es posible distinguir los directivos, que son los miembros más adultos (alrededor de los 30 años) que han participado en la creación de la Asociación y del proyecto Yumbo. Se ocupan de la gestión y organización de las actividades, de los proyectos locales e internacionales, de la gestión del local (abrir y cerrar) y son reconocidos por parte de los demás como los jefes.

En la escala jerárquica, inmediatamente después se encuentran los monitores: los demás miembros de la Asociación que son mayores (desde los 16 a los 25 años) y que, en diferente medida, participan también en la organización y en la gestión de los proyectos, sobre todo en Yumbo, conociendo así los aspectos más administrativos del desarrollo de las actividades.

A continuación se situarían los participantes más pequeños (de 8 a 15-16 años). La gran mayoría forma parte de Yumbo, el grupo de percusión, o ha formado parte de este $y$, aunque haya dejado el grupo, sigue frecuentando el local haya o no actividades. No se ocupan de la organización de los proyectos, pero sí participan en el desarrollo de las actividades (siempre se les pide su opinión sobre nuevas actividades o si son necesarios cambios en actividades ya desarrolladas, etc.) y, a 


\section{perifèria}

Número 13, diciembre 2010

www.periferia.name

su vez, en la decoración y mantenimiento (limpieza) del local.

Realmente, en la vida cotidiana del local y en el desarrollo de las actividades, estas distinciones jerárquicas no son tan marcadas. Sobre todo el rol de los monitores se define en diferentes maneras dependiendo de las situaciones y de las actividades.

Al preguntar un día a un chico de 14 años, que pertenece a Yumbo y pasa a veces por el local, quiénes son los monitores de la Asociación, de inmediato dijo los nombres de Rubén, Javi, Jose, Victor (los directivos), sólo después de un rato añadió otros dos chicos y, después de pensarlo un poco más, añadió a otra chica, subrayando que "esta también, cuando viene al local, porque no viene casi nunca". La sensación fue que el chico no tenía muy clara la estructura jerárquica de la Asociación, identificaba como monitores los más mayores pero no todos, como si dependiera de la situación y del momento.

La observación del etnógrafo se tiene que fijar en este tipo de matrices para poder captar la visión de los actores y de esta forma, poder inferir lentamente las diferencias de significados. Esta observación además puede ser confrontada con una entrevista, para que la percepción inicial sea confirmada.

Rubén, Javi, Jose, como los...ehh...que trabajan realmente en Samsara... [...] yo los dos...bueno, porque yo... no...bueno yo ayudo...soy monitora también en Yumbo, pero tampoco es que yo tenga un cargo... [...] Yo no soy monitora monitora, pero...pero, yo intento ayudar...es difícil...no es monitora, si no...porque es más un trabajo en equipo

(Entrevista a BK, Marzo de 2009)

Inf. 1: cuando decimos estos de monitores es más... los mayores

Inf. 2: más de referencia, sabes, para que tengan alguien de referencia... son todos

Inf. 1: los mayores, o sea, queremos decir como los mayores...

Inf. 2: los que estamos aquí en Chill Out cuando... (Ríe) [...] sabes, hay... 


\section{perifèria}

Número 13, diciembre 2010

www.periferia.name

hay monitores de todo, sabes, nosotros no somos tan como para echarles la bronca...

Inf. 1: bueno... nosotros... yo por ejemplo no suelo hacerlo mucho

(Entrevista a IR y NR, Marzo de 2009)

Estos fragmentos de entrevistas representan la manera que he utilizado para realizar las transcripciones ${ }^{5}$.

Después de escuchar una y otra vez las grabaciones para no perder ni un suspiro de lo dicho, he transcrito todo, ya que no sólo las palabras, sino las interrupciones y los elementos de duda permiten comprender la realidad que está detrás de las palabras. Como se verá a lo largo del artículo, en el transcribir las entrevistas he intentado reflejar de la mejor manera el desarrollo de las mismas, sin modificarlas para que fueran más literarias y correctas.

Está claro que en el artículo no he insertado las entrevistas completas, ya que es deber del etnógrafo diferenciar los datos importantes para la investigación de los que no lo son. Y esto en las entrevistas como en la observación.

El recurso a la selección de los pasos de las entrevistas y los fenómenos a observar es indicativo también del tipo de etnografía que se escribe. Etnografía como texto que puede ser entendida como historia final que involucra también la experiencia personal del investigador, una "nueva etnografía" (Goodall, 2000). O como creación narrativa exclusiva del antropólogo que no se limita a dar cuenta de lo observado (Clifford, 1991) y demuestra así la supremacía de su subjetividad y su experiencia en la interpretación de los hechos.

\footnotetext{
5 Para una mejor comprensión de los signos de puntuación utilizados en las transcripciones de las entrevistas, se añade aquí su significación: [...] = los tres puntos dentro de dos corchetes indican una parte de la entrevista que la autora ha excluido de la transcripción en el articulo;...$=$ los tres puntos indican un pequeño silencio;...ehh.../...mmm... = estas expresiones indican momentos de reflexión en el discurso explicitados con estos sonidos; $i !$ = los puntos exclamativos indican sonidos fuertes relativos a una frase o palabra del habla; (ríe) = Las palabras entre paréntesis son descripciones de la autora en lugar de transcripciones.
} 


\section{perifèria}

Número 13, diciembre 2010

www.periferia.name

En el estudio de caso presentado, he tenido siempre en consideración mi rol de investigadora en el campo y he reflexionado sobre mis selecciones a la hora de observar, escribir notas, entrevistar y transcribir. Sin embargo, a la hora de redactar el informe final he preferido transponer una representación de los hechos más objetiva posible, para evitar que mi subjetividad tuviese un predominio total. Los datos recopilados a través de los métodos etnográficos, me han permitido en el análisis pasar desde una percepción inicial a unos resultados más rigurosos para comprender el sistema de valores culturales que mueve la Asociación.

Por ejemplo, a través de la observación ha resultado evidente el hecho que las distinciones jerárquicas entre los grupos son poco definidas, como he indicado más arriba. Los jóvenes mayores (18-25 años) que participan desde hace poco tiempo a las actividades, son considerados como los pequeños. Como sostiene una informante "Los nuevos se les consideras más... ino monitores!" (Entrevista a BK, Marzo de 2009). Las distinciones entonces, más que basarse en la edad, se basan en la experiencia y en la participación activa que permiten el desarrollo de una mayor o menor responsabilidad.

Este valor tiene un peso importante en la construcción y en la definición de los roles: a través de la participación en la Asociación los miembros asimilan una mayor pertenencia al grupo, lo que les proporciona más obligaciones respecto a los demás, y también una mayor posesión del grupo y del espacio asociativo, lo que les lleva a tener más derechos. Se trata de un proceso que permite acumular experiencia a través de la participación, y la mayor experiencia lleva a tener más responsabilidades, o sea, más derechos y obligaciones.

Yo creo que... viene un poquito a raíz de... de la experiencia... o sea... No hay como una... un día clave o algo así, no? Ni el hecho de tener titulo de monitor de tiempo libre, no? Más a raíz de un proceso, no? Que... que te lleva a eso.... más experiencia y una responsabilidad, no? de lo que es el grupo y su funcionamiento.

(Entrevista a FD, Febrero de 2009) 


\section{perifèria}

Número 13, diciembre 2010

www.periferia.name

Este proceso, que a través de la participación lleva a la responsabilidad y permite diferenciar los roles internos, pasa por diferentes fases que permiten distinguir diferentes tipos de responsabilidades.

La mayoría de los informantes coinciden en afirmar que la responsabilidad crece con una mayor participación en la Asociación. Muchos de los pequeños que participan en el proyecto local del grupo de percusión Yumbo, acaban tomando parte a otras actividades organizadas por Samsara. Por ejemplo alguno ha viajado con los programas de intercambio o ha hecho la experiencia de los campos de trabajo internacionales o del Voluntariado Europeo. O al contrario acaban formando parte de Yumbo o de Samsara por haber participado antes a experiencias de este tipo. El hecho de recibir estas oportunidades por un lado aumenta la participación, y en consecuencia, la experiencia y la responsabilidad hacia la Asociación. Por otra parte crea un vínculo con la entidad que lleva a los participantes a involucrarse más, una especie de devolución por la posibilidad ofrecida.

La responsabilidad, formada por obligaciones y derechos, permite tener mayor libertad y un sentimiento de mayor igualdad. Son iguales porque tienen los mismos derechos y obligaciones. Al mismo tiempo son libres de participar y tomar parte en la Asociación. Esto explica por qué en la toma de decisiones se consideran siempre las iniciativas y las críticas de todos los miembros y por qué el local de Samsara es el espacio donde se concretiza esta libertad e igualdad de movimiento.

Nos encontramos en una escala de valores que empieza con la participación y acaba con la libertad. Es difícil afirmar qué valor está delante de otro, porque se trata más bien de una escala con varias ramificaciones que se cruzan entre sí y en algunos puntos convergen. Lo significativo es que en estos valores se hallan contravalores, en las personas que no forman parte de la Asociación pero que, por su relación de amistad, familiar o por ser simples conocidos, circulan alrededor de Samsara.

Mientras que los miembros activos actúan en base a estos valores considerados como positivos (se sienten más responsables hacia los demás; se involucran más en las actividades; utilizan el espacio de manera más libre y responsable; etc.), los 


\section{perifèria}

Número 13, diciembre 2010

www.periferia.name

que no forman parte de la Asociación sienten estos valores como restrictivos: no participan de la misma forma, por lo cual no tienen la misma responsabilidad ni la misma libertad, ya que su rol es lo de amigos-conocidos de otros miembros. No tienen el mismo sentimiento de posesión y pertenencia que es lo que otorga mayores obligaciones y derechos. Esto explica por qué, por ejemplo, no actúan de forma totalmente libre en el local y no tienen la misma relación de amistad con todos los miembros de la Asociación. No quiero decir que no tienen derecho a utilizar libremente el local, más bien tienen un derecho diferente: un derecho dado por el contra-valor de la libertad. Aunque no se trate de una libertad total, porque no está respaldada por una participación y una responsabilidad activa.

El local representa la parte física de la Asociación donde se recrean, dentro de unos límites materiales y espaciales, los valores que rigen el grupo humano.

Para los miembros activos se crea una relación a tres bandas regida por este conjunto de valores: el local, la Asociación y los usuarios miembros. Como resultado de una mayor participación y responsabilidad en la vida de la Asociación, las interacciones en el local se basan en una igualdad/libertad de utilización del espacio: cada uno conoce y respeta las reglas acerca del uso del local haciendo que haya mayor libertad y decisión de movimiento.

De hecho, he podido observar en repetidas ocasiones que cuando los más pequeños llegan al local, entran, saludan y sin pedir permiso y sin que nadie les pregunte nada, bajan directamente a la Ciber Aula, reconocida como la habitación de los más pequeños, se sientan en frente del ordenador y pasan allí un rato.

El lugar se siente de todos, sabes? Se sabe donde vienes, entonces los chicos saben que tienen su libertad... en su sala... Yumbo tiene su propia sala... ellos saben que no tienen que entrar aquí pero que... que en su sala... es su sala, sabes?

(Entrevista a DB, Abril 2009)

Se trata, por tanto, de un derecho de libertad de uso del espacio que se completa con la obligación de respetar otras reglas como, por ejemplo, la de no entrar en la 


\section{perifèria}

Número 13, diciembre 2010

www.periferia.name

Chill Out. En este espacio normalmente se reúnen los más mayores, directivos o/y monitores para hacer reuniones, o simplemente miembros o no de la Asociación, pero siempre gente de confianza, para pasar el rato. Aquí los pequeños y los nuevos no pueden entrar. Sobre todo a partir de las $21 \mathrm{~h}$. de la noche, cuando oficialmente el local cierra sus puertas y se quedan dentro unos pocos del grupo.

Inf.: Hombre, es que las nueve es el horario oficial, no, del local... a las nueve cerramos... los más pequeños se van... claro, si se van... y luego aquí nos podemos quedar los monitores... ya... pa' hablar de nuestras cosas... sabes? pa' estar aquí... [...] no vas a dejar aquí un niño... es que no son horas además que esté un niño de 11 años aquí a las nueve-diez de la noche tampoco...

Yo: ¿̇y si hay un chico de 20 años nuevo?

Inf.: hombre tampoco...

(Entrevista a IR y NR, Marzo de 2009)

Se trata entonces de un espacio dentro del espacio total del local reservado a los mayores, a personas que mantienen un vínculo de confianza que sobrepasa los límites de la Asociación.

En el caso de los no asociados se encuentra entonces otro tipo de estructura a tres bandas: con el local, con los usuarios y con los miembros de la Asociación. No con la Asociación en sí, ya que no toman parte en sus actividades, pero sí se relacionan con sus asociados. Una estructura regida por los contra-valores que se completa con el vínculo de la amistad: el saber que es un lugar donde, aunque no se sienta totalmente como propio, existen vínculos afectivos que permiten su uso.

Aunque no tenga añadido el valor de la participación activa, el hecho de conocer a alguien dentro de la Asociación y del local hace que el espacio se reconozca en parte como propio, tanto para poder afirmar que el contra-valor de la participación está en estos casos reemplazado por el valor de la amistad.

En el caso de los no asociados he tenido que hacer gran uso de la observación para 


\section{perifèria}

Número 13, diciembre 2010

www.periferia.name

llegar a reconocer cómo se estructuraban las relaciones de valores. Ver cómo se movían dentro del local era algo que reclamaba fuertemente mi atención y el esfuerzo consistió no solamente en mirar, más bien en contemplar y examinar atentamente sus actos para determinar su naturaleza y su funcionamiento dentro del espacio social, a través de una observación minuciosa. Una observación que buscaba comprender cómo los valores estaban encarnados en sus conductas, ya que el valor hay que contemplarlo en el momento de su aplicación, y en estos casos, una de sus aplicaciones era el comportamiento dentro del local.

Como muchos de los informantes alegan, el local es frecuentado por un considerable número de personas diferentes, más o menos conocidas, que reproducen en el uso del espacio los valores que rigen sus interacciones y sus actuaciones. Todo este movimiento de personas hace que la Asociación asuma un aspecto más informal, presentándose como una amplia comunidad de personas vinculadas entre sí por diferentes aspectos y que interaccionan cada una siguiendo los valores y los contra-valores propios de la situación y de los vínculos.

Se puede hablar de un proceso inverso a lo que diferentes autores han percibido en la relación entre cuadrillas de amigos y asociacionismo voluntario ${ }^{6}$. En este caso se delinea un proceso guiado por los vínculos de amistad entre los actores pertenecientes a una cuadrilla de amigos, que influencian y fomentan la creación de nuevas asociaciones. En el caso aquí presentado, se trataría de un proceso inverso, donde las relaciones de valores que se crean entre los que pertenecen en mayor o menor medida a la vida asociativa, acaban creando una comunidad de amigos.

Hay gente que... que se pasa al local para estar... que vienen al local para echar, no se, jugar un poco de futbolín o estar con... porque conocen a gente que va a Yumbo y que está siempre allí... como que vienen también a pasar... pasan también el rato y también les conocemos pero... ya no vienen a Yumbo o nunca han venido

(Entrevista a BK, Marzo de 2009) 


\section{perifèria}

Número 13, diciembre 2010

www.periferia.name

Es como... una comunidad entera de Samsara, no? no hablaremos de Asociación, si no comunidad casi... entonces bueno, ya... seas del barrio centro o del barrio norte... siempre es un punto de conexión, no? el local aquí. Asociación.... y tal sí... pero luego es una red... impresionante, no? [...] no sólo la amistad van a ser los miembros, no? Ni... si eres mi amigo eres miembro, no... sino que... es un círculo muy grande de tipos de amigos, no? Pero se podría decir que... que serían... también... toda la red de... de gente que se pueden unir a lo mejor en un momento dado como... con el espacio Samsara como... centro, no? De... de la reunión.

(Entrevista a FD, Febrero de 2009)

El local de Samsara, de este modo, representa un lugar de encuentro que reúne los valores y los contra-valores que incitan a sus usuarios a la interacción y que explican por qué existe un diferente uso y una diferente simbolización valorativa entre el local de la Asociación Samsara y los espacios públicos del Ayuntamiento.

En varias ocasiones, al preguntar sobre las actividades y los espacios públicos del Municipio, los entrevistados/as revelan las diferencias de objetivos en sus usos. Se deja a entender que los lugares públicos del Ayuntamiento, por ejemplo la Casa de la Juventud, son frecuentados con unos objetivos específicos: participar en un torneo de ping pong o de Play Station; ir a talleres o cursos, etc.

En cambio el local de la Asociación Samsara asume la identidad de lugar para estar: estar por estar. Un lugar donde toda la red de personas que gira alrededor de la Asociación encuentra un sitio de confianza, una confianza que nace a través de la participación y/o de la amistad, y donde esta confianza permite utilizar el espacio aunque sea solamente para el placer de estar. Un estar por estar que de ser una actividad negativa, síntoma de perder el tiempo, se convierte en un estar por estar positivo, donde el tiempo no se pierde, más bien se disfruta de ello y se convierte en tiempo para sí mismo.

En los centros públicos las actividades están diseñadas y organizadas por los propios técnicos del Ayuntamiento y esto no permite que nazca un sentimiento real 


\section{perifèria}

Número 13, diciembre 2010

www.periferia.name

de apropiación y posesión de la actividad y del espacio. La participación se revela como participación pasiva y, faltando el elemento de amistad que es lo que en el caso de Samsara une los no participantes con la Asociación, los valores de experiencia y responsabilidad no tienen un carácter fundamental $y$, sin esos, tampoco se encuentran la libertad y la igualdad que mueven a la acción.

Al contrario, en el espacio de Samsara estos valores son los que activan la acción de pasar un rato en el local, donde el estar un rato asume un significado positivo, se convierte en una apropiación del tiempo para estar con uno mismo y compartir este propio tiempo con los demás.

Siempre mola estar aquí con los amigos y siempre... aunque no tenga nada que hacer en casa, puedes venir aquí y algo sale pa' hacer... pues... o estar aquí vamos, con... hablar un poco, y como va la semana, con los compañeros, a lo mejor sale de tocar y vas...

(Entrevista a DB, Abril de 2009)

\section{Conclusiones}

El objetivo de la investigación era detectar las relaciones de valores estudiando la realidad de una Asociación. Para esto, ha sido necesario tener claro cuál es la forma y la composición de las figuras de valor: los valores son modelos culturales de determinados principios morales de conducta que rigen nuestras identidades y nuestro estar en el mundo; varían en función del lugar y de la historia, lo que significa que conservan su significado solamente dentro de la sociedad que forma el sistema de valores, y se trasmiten en los momentos en los que los actores sociales los ejemplifican en sus conductas. Si los valores son los principios que permiten al ser humano decidir y juzgar la realidad, si son a través de ellos que se genera una voluntad que da paso a la acción, significa que se pueden reconocer por qué se encarnan en la conducta. Si no hubiera tomado como punto de partida esta concepción de los valores, nunca los habría podido encontrar en los hechos. Además, esto representa la perspectiva teórica que ha sido necesaria para el desarrollo de la investigación, como sostén de las prácticas etnográficas del trabajo 


\section{perifèria}

Número 13, diciembre 2010

www.periferia.name

de campo.

Por otra parte, el objetivo del artículo no ha sido ofrecer un conjunto de reglas determinadas a modo de guía metodológica para los investigadores, ya que presumo que cada antropólogo utilizará y aplicará diferentes técnicas en su trabajo de campo siguiendo una determinada perspectiva teórica que ha hecho suya.

Tener una perspectiva teórica no significa tener ideas preconcebidas, que son perniciosas para el trabajo. Significa tener una preparación teórica que acompañe el trabajo de campo y nos oriente en la investigación. Esta perspectiva teórica también configura un trabajo de investigación como un trabajo antropológico.

En estos últimos años, la mayoría de los antropólogos y antropólogas afirman que nos encontramos en una época de interdisciplinariedad en la investigación, por lo cual es difícil afirmar que unas u otras técnicas son propias sólo y exclusivamente de una u otra disciplina. Efectivamente, son muchas las investigaciones antropológicas en la que se ha hecho uso de estadísticas, encuestas y cuestionarios, así como ya son muchos los estudios de otras disciplinas, como sociología, historia o ciencia política, donde se utiliza la entrevista en profundidad y la observación participante. Entonces ¿qué es lo que diferencia una investigación antropológica de una sociológica o histórica? Es la perspectiva teórica del investigador y su manera de abordar el objeto de estudio. En realidad no son las técnicas en sí, sino la manera en que se utilizan y el objetivo por el que se utilizan. La diferencia está en la "mirada" que hace que los datos y los resultas producidos por iguales técnicas sean diferentes. En el caso de nuestra disciplina, las técnicas etnográficas son más válidas y dan resultados más cualitativos siempre que partan de una mirada especial: la mirada antropológica (Jociles, 1999).

La metodología al fin y al cabo es aquella parte que permite la producciones de datos sobre los cuales enfocar el análisis y si el estudio utiliza las mismas técnicas pero de perspectivas diferentes, es normal que los datos resultantes también serán diferentes.

En fin, en este artículo se ha intentado resaltar la importancia de la metodología etnográfica, no tanto para elevarla a símbolo y elemento de estatus de la 


\section{perifèria}

Número 13, diciembre 2010

www.periferia.name

antropología, cuanto para demostrar como su uso oportuno, y orientado por una perspectiva teórica y una mirada antropológica, permite el eficaz desarrollo del estudio.

\section{Bibliografía}

Asad, Talal (1991). "El concepto de la traducción cultural en la antropología social británica" en Clifford, James y Marcus, George E., Eds. (1991) Retóricas de la antropología. Barcelona: Ediciones Júcar, 205-234.

Barley, Nigel (1989). El Antropólogo inocente. Barcelona: Editorial Anagrama.

Clifford, James y Marcus, George E., Eds. (1991). Retóricas de la antropología. Barcelona: Ediciones Júcar.

Crapanzano, Vincent (1991). "El dilema de Hermes" en Clifford, James y Marcus, George E., Eds. (1991) Retóricas de la antropología. Barcelona: Ediciones Júcar, 91-122.

Cucó, Josepa (1991). El quotidià ignorat. La trama asociativa valenciana. Valencia: Edicions Alfons El Magnànim - Istitució Valenciana d 'Estudis i Investigació. (1995). La amistad: perspectiva antropológica. Barcelona: Icaria.

Del Olmo, Margarita (2003). "La construcción de la confianza en el trabajo de campo. Los límites de la entrevista dirigida". Revista de Dialectología y Tradiciones Populares, LVIII (1):191-220.

De Martino, Ernesto (1977). La fine del mondo. Contributo all'analisi delle apocalissi culturali, Torino: Einaudi.

Freilich, Morris (1970). Marginal natives: Anthropologist at work. New York: Harper \& Row.

García Canclini, Néstor (1991). "¿Construcción o simulacro del objeto de estudio? Trabajo de campo y retórica textual". Alteridades, 1(1): 58-64.

García Selgas, Fernando J. (1990). "La corregibilidad de la «observación participante»: una reflexión sobre la sociología actual". Política y sociedad, 6/7: 85- 


\section{perifèria}

Número 13, diciembre 2010

www.periferia.name

102.

Geertz, Clifford (1988). La interpretación de las culturas. Barcelona: Gedisa

Gil, Fernando (1998). "La bonne description". Enquête, La description I, 6: 129-152

Goodall, Harold Lloyd (2000). Writing the new ethnogaphy. Lanham: AltaMira Press/Rowman \& Littlefield.

Greenwood, Davydd J. (2000). "De la observación a la investigación-acción participativa: una visión critica de las prácticas antropológicas". Revista de Antropología Social, 9: 27-49.

Guber, Rosana (1991). El salvaje metropolitano. Reconstrucción del conocimiento social en el trabajo de campo. Buenos Aires: Legasa.

Hammersley, Martyn y Atkinson, Paul (1994). Etnografía: métodos de investigación. Barcelona: Paidós.

Harris, Marvin (1985). El materialismo cultural. Madrid: Alianza Editorial.

Homobono, Jose Ignacio (1994). "Grupos y asociaciones amicales. La sociabilidad en Euskal Herria". Inguruak. Revista de Sociología, 8: 231-253.

Jociles Rubio, María Isabel (1997). "Nigel Barley y la investigación etnográfica". Política y Sociedad, 24: 97-120.

(1999). "Las técnicas de investigación en Antropología. Mirada antropológica y proceso etnográficos". Gazeta de Antropología, 15.

Krotz, Esteban (1991). "Viaje, trabajo de campo y conocimiento antropológico". Alteridades, 1(1): 50-57.

Lanternari, Vittorio (1997). L'incivilimento dei barbari: identità, migrazioni e neorazzismo. Bari: Dedalo.

Laplantine, François (1996). La description ethnographique. Paris: Éditions Nathan. Lewis, Oscar (1975). "Controles y experimentos en el trabajo de campo" en La antropología como ciencia. Llobera Josep R., Comp. (1975) Barcelona: Editorial Anagrama: 97-128. 


\section{perifèria}

Número 13, diciembre 2010

www.periferia.name

Lisón Tolosana, Carmelo (2000a). "Informantes: in-formantes". Revista de Antropología Social, 9:17-26.

Ed. (2000b). Antropología: horizontes interpretativos. Granada: Universidad de Granada.

Llobera, Josep R. (1990). La identidad de la antropología. Barcelona: Editorial Anagrama.

Malinowski, Bronislaw (1973). "Introducción: objeto, método y finalidad de esta investigación" en Los Argonautas del Pacifico Occidental. Barcelona: Ediciones Península: 19-42.

Mancinelli, Fabiola (2008). "La etnógrafa-guía. Técnicas y metodología de investigación". (con)textos. Revista d'antropologia i investigación social, 2: 103110.

Olivier de Sardan, Jean-Pierre (1995). "La politique du terrain. Sur la production des dones en anthropologie". Enquête, Les terrains de l'enquête, 1: 71-109.

Palacios Ramírez, José (2006). "Comentarios reflexivos sobre la praxis del trabajo de campo". Revista de Antropología experimental, 6: 95-105.

Pannof, Michel y Pannof, Françoise (1975). "¿Para qué sirve la etnografía?" en Llobera Josep R., Comp. (1975) La antropología como ciencia. Barcelona: Editorial Anagrama: 79-84.

Sanmartín Arce, Ricardo (1999). Valores culturales. El cambio social entre la tradición y la modernidad. Granada: Editorial Comares.

(2000). "La entrevista en el trabajo de campo". Revista de Antropología Social, 9: 105-126.

(2003). Observar Escuchar Comparar Escribir. La práctica de la investigación cualitativa. Barcelona: Editorial Ariel.

(2007). "La calidad en la investigación antropológica". Revista de Dialectología y Tradiciones Populares, LXII (2):7-20. 


\section{perifèria}

Número 13, diciembre 2010

www.periferia.name

Signorini, Italo, Ed. (1998). I modi della cultura. Roma: Carocci editore.

Velasco, Honorio y Díaz de Rada, Ángel (1997). La lógica de la Investigación Etnográfica. Madrid: Ed. Trotta.

Wolcott, Harry F. (1994). Transforming Qualitative Data: Description, Analysis, and Interpretation. London: Sage.

(2007). "Etnografía sin remordimientos". Revista de Antropología Social, 16: $279-296$. 